\title{
RAPPORTS DES COMITES NATIONAUX DE LA LIGUE INTERNATIONAL CONTRE L'EPILEPSIE.
}

\section{BERICHT ÜBER DIE EPILEPTIKERPFLEGE IN SCHWEDEN.}

Mit Gegenwärtigem sende ich Ihnen den gewünschten Bericht über die Epileptikerpflege in Schweden, obschon leider nicht viel hierüber zu sagen ist.

Nach unserem Irrengesetz, das 2 Arten staatlicher Anstalten für Geisteskranke, Heilanstalten und Pflegeanstalten, voraussetzt, dürfen in die letztere Art von Irrenanstalten auch Epileptiker aufgenommen werden, und zwar wenn diese auf Grund zeitweilig auftretender Geisteskrankheit für sich oder andere gefăhrlich sind. In den 3 Pflegeanstalten, die es hierzulande gibt, betrug demnach Ende des Jahres rgog die Anzahl Epileptiker resp. 5,2 4,4 und I,6\% der sämtlichen Insassen, während außerdem diejenigen in den Irrenanstalten, welche den Charakter von sowohl Heil- als Pflegeanstalten haben, zur selben Zeit $\mathrm{I}, 9$ bis $2,5 \%$ der in diesen untergebrachten Kranken betrugen. Die ganze Anzahl mit Epilepsie Behafteter, die Ausgangs des Jahres 1909 in den staatlichen Irrenanstalten gepflegt wurden, betrug in Summa 148, und zwar 97 Männer und $5^{\mathrm{I}}$ Frauen.

Außer staatlichen Irrenanstalten gibt es indessen bei uns teils eine größere, zur Stadt Stockholm gehörige Irrenanstalt teils auch bei den Armenflegeanstalten mehrerer größerer Städte besondere Irrenabteilungen. In der ersteı en Anstalt befinden sich einige 20 Epileptiker, während von der letzteren diesbezügliche Angaben nicht vorliegen.

$\mathrm{DaB}$ die nun angegebenen Zahlen nicht dem Bedarf an Plätzen für solche Epileptiker entsprechen, die - sei es auf 
Grund eines stationären Zustandes von hochgradiger Reizbarkeit des Gemütes verbunden mit mehr oder weniger ausgesprochener Demenz oder infolge von häufig eintretenden Dämmerungszuständen - beständiger Wartung in einer geschlossenen Anstalt bedürfen, dürfte keinem Zweifel unterliegen. In Schweden herrscht indessen noch großer Mangel an Plătzen in Irrenanstalten. Während über roo0o solche als erforderlich angesehen werden, sind noch nicht völlig 7000 in allen staatlichen Anstalten zusammengenommen vorhanden.

Auch in bezug auf die Idiotenanstalten gilt, daß die Anzahl Plätze für Epileptiker durchaus unzureichend ist. $\mathrm{Da}$ es Vorschrift ist, daß bildungsfähige Idioten, welche mit Epilepsie behaftet sind, nicht in dieselben Anstalten aufgenommen werden dürfen wie andere bildungsunfähige Idioten, können erstere keinen Einlab erhalten in die von den verschiedenen Lehn errichteten Idiotenschulen (welche alle bis auf eine einzige Internate sind.) Von 2 für den Zweck gegründeten Vereinen sind daher Erziehungsanstalten ausschließlich für mit Epilepsie behaftete bildungsfähige Idioten eingerichtet. Von diesen Anstalten (welche beide Internate sind) hat die eine 45 Plätze, die andere wiederum (welche doch binnen kurzem erweitert werden dürfte) nur II Plätze. Für diese Anstalten waren Ausgang des Jahres 1909 Exspektanten in einer nahezu ebenso großen Anzahl vorhanden wie die gesamte Platzanzahl. Die Beschaffung einer größeren Anzahl Plätze für mit Epilepsie behaftete bildungsfăhige Idioten ist also dringend nötig.

In den Anstalten für bildungsunfähige Idioten, wovon es Ausgang des Jahres Igog hierzulande deren I5 gab - zum Teil von für den Zweck gegründeten Vereinen oder von Privatpersonen errichtet, zum Teil wiederum von den Lehn im Anschlub an ihre Idiotenschulen eingerichtet - mit insgesamt 378 Plätzen, müssen natürlich epileptische und nicht epileptische Idioten zusammen gepflegt werden. Wie viele von den erwähnten Plätzen mit 
an Epilepsie Leidenden belegt sind, darüber liegt indessen keine Angabe vor. Dagegen bringen die Jahresberichte aus diesen Anstalten dieAnstalten der Epileptiker unter den Neuaufgenommenen. Von den während des Jahres Igog in sämtliche hier in Rede stehenden Anstalten Aufgenommenen, deren Anzahl II 7 beträgt, waren 29 mit Epilepsie behaftet, also etwa $25 \%$ der ganzen Anzahl entsprechend.

Am allerwenigsten ist hierzulande für solche Epileptiker getan, die weder geisteskrank noch Idioten sind, indem für zwischen den Anfällen „normale“ Epileptiker bislang nur ein kleines Epileptikerheim mit 20 Plätzen existiert, das von der Schwedischen Diakonengesellschaft bei deren außerhalb Stockholm gelegener Anstalt zur Ausbildung von Diakonen errichtet ist.

Daß die eigentlicheEpileptikerpflege bei uns so verabsäumt worden ist, findet seine Erklärung darin, daß der Staat sich derselben in keiner Weise angenommen hat. Was die Idiotenflege anbelangt, so hat der Staat freilich auch diese nicht direkt in die Hand genommen, wie er es bei der Irrenpflege getan hat, unterstützt sie aber doch in sehr kräftiger Weise, indem für jeden in eine von der zuständigen Behörde gutgeheißene Idiotenanstalt aufgenommenen Idioten ein staatlicher Beitrag von $25^{\circ}$ Kronen gewăhrt wird (seit dem Jahre I8g8 für Bildungsfähige und seit dem Jahre I905 auch für Bildungsunfähige). Man geht nun mit der Absicht um, im Reichstage einen Antrag anzuregen, dahingehend, daß die gleiche Unterstützung auch für jeden in eine Spezialanstalt aufgenommenen Epileptiker gewährt werden soll, indem man auf Grund der Erfahrung von dem Aufschwung, den die Idiotenpflege der Bewilligung des erwähnten Budgets erhielt, die Hoffnung hegt, hierdurch eine höchst notwendige Entwickelung der Epileptikerpflege in die Wege zu leiten.

Privatdozent Dr. Alfred Petrén. 